\title{
Prototipe Monitoring Suhu dan Kelembaban dalam Pengolahan Air Menggunakan SHT11
}

\author{
Humaidillah Kurniadi Wardana \\ Teknik Elektro, Fakultas Teknik, Universitas Hasyim Asy’Ari dan Alamat e-mail: adi3_wardana@yahoo.com
}

\begin{abstract}
Abstrak
Telah berhasil dirancang dan dibuat prototipe monitoring suhu dan kelembaban dalam pengolahan air. Sistem monitoring dibuat menggunakan sensor SHT 11 dihubungkan dengan rangkaian minimum ATMega 16 yang ditampilkan pada LCD 16x2 sebagai keluaran output. Pengambilan data dilakukan sebanyak 3 kali pengukuran dengan tiap pengukuran diambil data sebayak 10 kali selama 10 menit. Tiap pengukuran dari pertama ke pengukuran kedua maupun ketiga memiliki rentang waktu 1 jam
\end{abstract}

Kata Kunci: Air, Suhu, Kelembaban, SHT11, ATMega16.

\section{Abstract}

Has successfully designed and made the prototype of monitoring the temperature and humidity in water treatment. Monitoring system created using sensors linked to a series of 11 SHT minimum ATMega 16 displayed on LCD $16 \times 2$ as output. Data retrieval is done by as much as 3 times measurement measurement taken with each data sebayak 10 times for 10 minutes. Each measurement from the first to the second or third measurement has a span of 1 hour

Keywords: Water, Temperature, Humidity, SHT11, ATMega16.

\section{PENDAHULUAN}

Air merupakan elemen penting yang dibutuhkan oleh semua makhluk hidup yang ada di bumi. Manfaat air yang paling utama dan sangat penting bagi kehidupan adalah sebagai kebutuhan air minum dan tidak bisa ditunda dalam pemenuhannya (Kumalasari, 2013). Air minum adalah air yang melalui proses pengolahan atau tanpa pengolahan yang memenuhi syarat kesehatan dan dapat langsung diminum (Kemenkes RI, 2010).

Air minum dapat diperoleh dari berbagai sumber, misalnya dari mata air pegunungan, air sumur, air laut, air sungai, air danau dan lain sebagainya. Tidak semua air yang terdapat di alam langsung bisa diminum. Hanya air bersih dan diolah secara higienis dan bebas dari mikroorganisme layak untuk dikomsumsi. Menurut keputusan menteri kesehatan RI NOMOR 907/MENKES/SK/VII/2002 tentang air dengan kualitas layak diminum mempunyai standart persyaratan tertentu diantaranya secara fisis seperti rasa, bau, warna, jumlah zat terlarut, suhu, kekeruhan. Secara kimiawi seperti aluminium, besi, kesadahan, klorida, mangan, $\mathrm{pH}$, sulfat, tembaga, ammonia. Parameter bakteriologis dan kimia anorganik seperti E. Coli, total koliform, arsen, fluoride, kromium-val.6, cadmium, sianida, dan selenium.

Air tanah merupakan sejumlah air di bawah permukaan bumi yang dapat dikumpulkan dengan sumursumur, terowongan atau sistem drainase atau dapat juga disebut aliran yang secara alami mengalir ke permukaan tanah melalui pancaran atau rembesan (Robert J Kodoatie, 1996 ). Air sumur atau disebut juga dengan air tanah mempunyai karakteristik yang berbeda dengan kualitas air permukaan atau sungai. Air tanah pada umumnya jernih tetapi mengandung mineral-mineral serta garam yang cukup tinggi, sebagai akibat dari pengaruh batuan bawah tanah yang dilaui oleh air tanah (Endarko dkk, 2013). Untuk mendapatkan air sumur yang siap diminum maka salah satunya dilakukan pengolahan air secara tradisonal yaitu dengan cara dimasak. Air dididihkan hingga mencapai suhu $100^{\circ} \mathrm{C}$. Biasanya kebiasaan ini dilakukan oleh penduduk - penduduk di pedesaan dengan tujuan membunuh kuman - kuman dan mikroorganisme dan pada akhirnya air sumur dapat dikomsumsi.

Beberapa penelitian yang telah dilakukan dalam pengelolaan air minum diantaranya: sistem penjernihan dan dekontaminasi air sungai layak minum berbasis biosand filter dan lampu ultraviolet (Rachmat Quddus, 2014), pengolahan air bersih dengan sistem saringan pasir lambat yang bersumber dari sungai musi (Sarikusmayadi, Astri Aprillia, 2015), pengelolaan air portable dalam kondisi darurat menggunakan membran mikrofiltrasi, ultrafiltrasi dan reverse osmosis (Renny Rakhmawati dkk, 2014), pengelolaan air laut menjadi air tawar dengan prinsip reverse osmosis berbasis mikrokontroler (Untari dkk, 2015), pengolahan air hujan sebagai air layak komsumsi dengan metode modifikasi filtrasi sederhana (Handriyanto, 2010).

Oleh karena itu diperlukan sistem pengolahan air sumur hingga layak digunakan untuk kebutuhan seharihari. Fokus utama dalam penelitian ini adalah mengolah air sumur dengan cara dimasak dan diukur parameter suhu dan kelembaban air tersebut menggunakan sensor sehingga memenuhi salah satu syarat untuk layak diminum. 


\section{METODE}

Metode yang digunakan dalam penelitian ini adalah mengolah air sumur dengan cara dimasak dan bisa dikomsumsi. Air sumur yang dimasak nantinya diukur paremeter suhu dan kelembabannya menggunakan sensor. Maka kegiatan penelitian terdiri dari: (1) merancang proses pengolahan air (Gambar 1) dan (2) merancang prototipe pengukuran suhu dan kelembaban (Gambar (2).

Perancangan prototipe sistem monitoring pengolahan air menggunakan alat pemanas atau heater yang dipergunakan untuk memanaskan air, SHT 11 sebagai sensor pengukur suhu dan kelembaban, rangkaian minimum mikrokotroler ATMega16 digunakan untuk mengolah sistem monitoring, dan lcd 16x2 berfungsi sebagai display output hasil pengukuran suhu dan kelembaban.

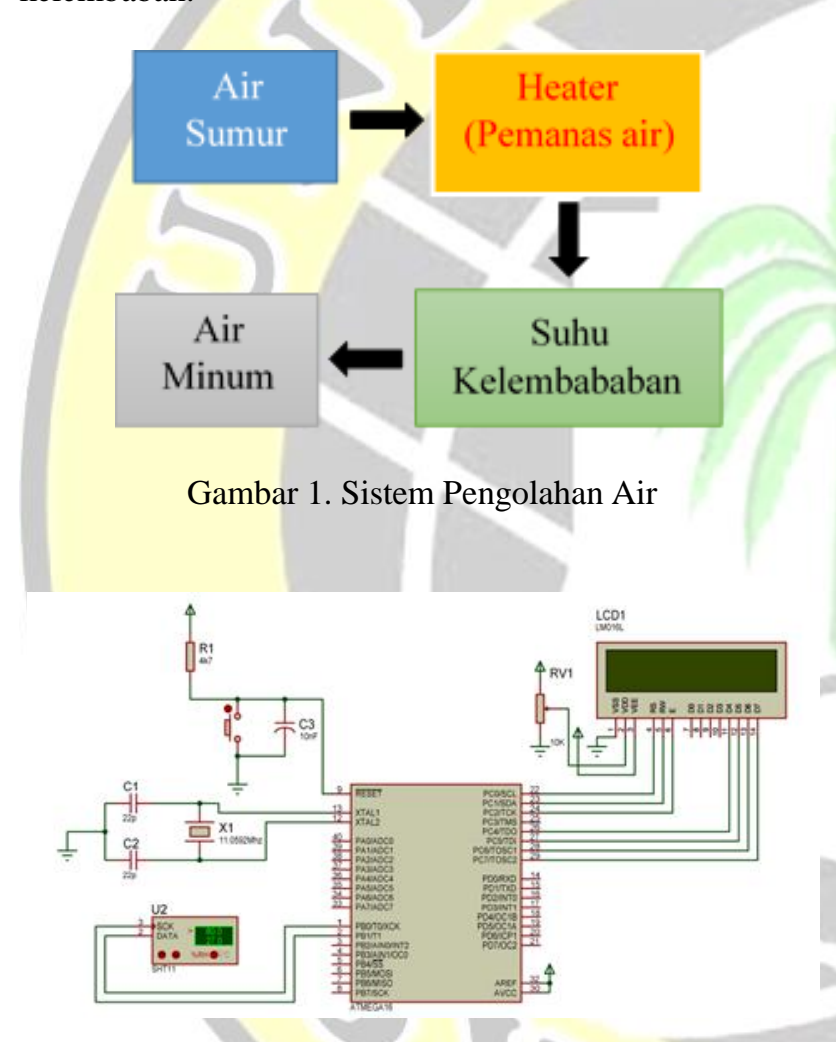

Gambar 2. Sistem Monitoring Pengolahan Air

Pengukuran suhu dan kelembaban dari sensor SHT 11 nantinya dibandingkan dengan hasil pengukuran suhu dan kelembaban dari termohigrometer digital tipe THD5. Pengambilan data dilakukan sebanyak 3 kali pengukuran dengan tiap pengukuran diambil data sebayak 10 kali selama 10 menit. Tiap pengukuran pertama ke pengukuran kedua memiliki rentang waktu 1 jam.

Nilai rata-rata ditentukan dari tiap pengukuran ke 1, 2, 3 pada menit yang sama dibagi banyaknya melakukan pengukuran dinyatakan dalam $(\mathrm{x} \pm \Delta \mathrm{x})$. Kemudian dicari standart deviasinya dengan rumus:

$$
s=\sqrt{\frac{\Sigma(X i-\bar{X})^{2}}{n-1}}
$$

\section{HASIL DAN PEMBAHASAN}

Prototipe monitoring suhu dan kelembaban pengolahan air ditunjukkan pada Gambar 3. Prototipe pengolahan air ini dibuat dengan menggunakan ceret sebagai wadah tempat air sumur yang akan dimasak. Dimana di dalam ceret sudah dilengkapi heater yang berfungsi sebagai pemanas air. Letak dari heater itu sendiri berada di dasar wadah. Air sumur yang dimasukkan ke dalam ceret sebesar $800 \mathrm{ml}$.

Sensor SHT 11 diletakkan tepat ditengah layung melekat pada tutup heater. Sedangkan termohigrometer yang dijadikan sebagai alat pembanding dalam pengambilan data suhu dan kelembaban yang juga diletakkan ditengah layung berdekatan dengan sensor SHT 11.

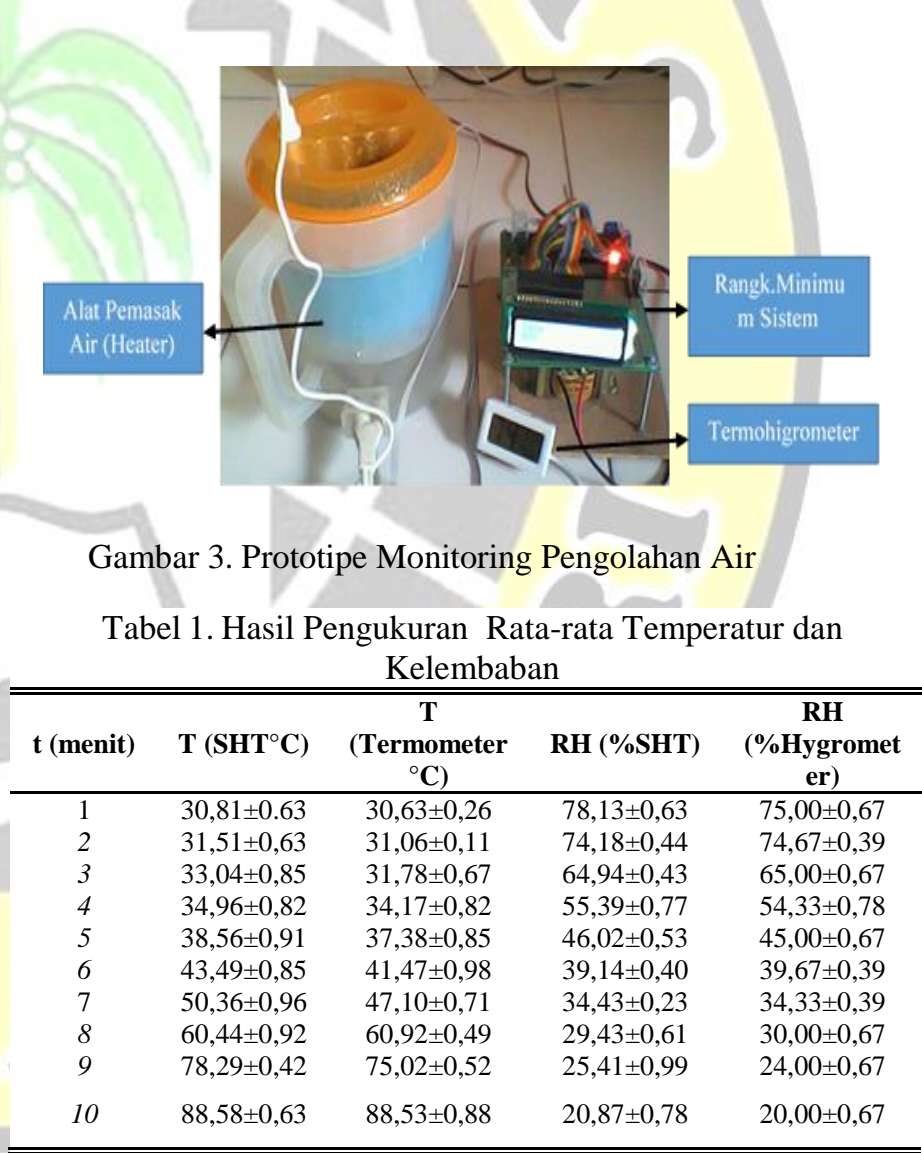

Semakin lama pelayuan semakin tinggi suhu yang dihasilkan dan kelembapan semakin menurun.

Pada tabel 1 merupakan hasil rata-rata pengukuran suhu dan kelembaban yang dihasilkan dalam pengukuran serta tabel 2 merupakan hasil perhitungan standar deviasinya. 
Tabel 2. Standar Deviasi Temperatur dan Kelembaban

\begin{tabular}{ccccc}
\hline \hline $\begin{array}{c}\mathbf{t} \\
(\mathbf{m e n i t}\end{array}$ & $\begin{array}{c}\mathbf{T} \\
\mathbf{S H T}^{\circ}\end{array}$ & $\begin{array}{c}\mathbf{T} \\
\mathbf{S}^{\text {Termometer }}{ }^{\circ}\end{array}$ & $\begin{array}{c}\text { RH (\% } \\
\mathbf{C H T})\end{array}$ & $\begin{array}{c}\text { RH }(\% \\
\text { Hygrometer) }\end{array}$ \\
\hline 1 & 0,94 & 0,39 & 0,93 & 1,00 \\
2 & 0,94 & 0,16 & 0,65 & 0,58 \\
3 & 1,27 & 0,99 & 0,64 & 1,00 \\
4 & 1,22 & 1,22 & 1,14 & 1,15 \\
5 & 1,34 & 1,26 & 0,78 & 1,00 \\
6 & 1,26 & 1,46 & 0,59 & 0,58 \\
7 & 1,42 & 1,05 & 0,35 & 0,58 \\
8 & 1,36 & 0,73 & 0,90 & 1,00 \\
9 & 0,62 & 0,77 & 1,47 & 1,00 \\
10 & 0,93 & 1,30 & 1,16 & 1,00 \\
\hline \hline
\end{tabular}

Setiap suhu dan kelembaban memiliki stadar deviasi berbeda-beda.

Didapatkan nilai rata-rata menit pertama dari suhu SHT 30,81 $\pm 0,63{ }^{\circ} \mathrm{C}$, suhu termometer sebagai pembanding sebesar $30,63 \pm 0,26{ }^{\circ} \mathrm{C}$. Sedangkan nilai rata-rata menit kesepuluh dari suhu SHT tercapai $88,58 \pm$ $0,63{ }^{\circ} \mathrm{C}$ dengan suhu termometer sebesar $88,53 \pm 0,88^{\circ} \mathrm{C}$. Kelembaban sht pada menit pertama sebesar 78,13 $\pm 0,63$ dan kelembaban higrometer 75,00 $\pm 0,67$ sedangkan menit kesepuluh kelembaban sht sebesar 20,87 $\pm 0,78$ dan kelembapan higrometer 20,00 $\pm 0,67$.

Air bersih adalah air yang digunakan untuk keperluan sehari-hari yang kualitasnya memenuhi syarat kesehatan dan dapat diminum apabila telah dimasak (Sitanala Arsyad, 1989). Semakin lama waktu yang dibutuhkan untuk melakukan pemanasan air maka semakin tinggi suhu yang tercapai. Ini sesuai dengan suhu yang diperbolehkan sebagai air yang layak dikomsumsi. Air yang baik harus memiliki temperatur sama dengan tempertur udara $\left(20{ }^{\circ} \mathrm{C}\right.$ sampai dengan $\left.60{ }^{\circ} \mathrm{C}\right)$. Air yang secara mencolok mempunyai temperatur di atas atau di bawah temperatur udara berarti mengandung zat-zat tertentu (misalnya fenol yang terlarut di dalam air cukup banyak) atau sedang terjadi proses tertentu (proses dekomposisi bahan organik oleh mikroorganisme yang menghasilkan energi) yang mengeluarkan atau menyerap energi dalam air (Sitanala Arsyad, 1989).

Tujuan dari memasak air untuk membunuh bakteribakteri yang ada di dalam air yaitu salah satunya bakteri Escherichia coli. Suhu optimum untuk pertumbuhan Escherichia coli $37^{\circ} \mathrm{C}$ tetapi Escherichia coli juga mampu tumbuh pada kisaran suhu yang lebar yaitu antara $15^{\circ} \mathrm{C}$ $45^{\circ} \mathrm{C}$. Strain Escherichia coli juga dapat bertahan pada pemanasan pada suhu $55^{\circ} \mathrm{C}$ selama 60 menit dan bahkan pada suhu $60^{\circ} \mathrm{C}$ selama 15 menit ( GA Willshaw, 2000).

\section{PENUTUP}

Simpulan

Berdasarkan hasil yang di dapatkan selama pengukuran seluruh sistem dalam penelitian ini dapat diambil beberapa kesimpulan:

1. Sistem monitoring suhu dan kelembaban pengolahan air dapat menggunakan SHT 11 sebagai sensor untuk mengukur suhu dan kelembaban.

2. Pengukuran dilakukan sebanyak 3 kali pengukuran selama 10 menit dan diambil nilai rata-rata dan standart deviasinya. Nilai rata-rata menit pertama dari suhu sht $30,81 \pm 0,63$, suhu termometer $30,63 \pm 0,26$, kelembapan sht $78,13 \pm 0,63$ dan kelembaban higrometer 75,00 $\pm 0,67$ sedangkan nilai rata-rata menit akhir dari suhu sht 88,58 $\pm 0,63$, suhu termometer $88,53 \pm 0,88$, kelembaban sht $20,87 \pm$ 0,78 dan kelembapan higrometer 20,00 $\pm 0,67$.

3. Stadar deviasi yang dihasilkan pada menit pertama dari sht 0,94, termometer 0,39, kelembaban sht 0,93, higrometer 1,00 sedangkan pada menit akhir dari sht 0,93 , termometer 1,30 , kelembaban sht 1,16 , higrometer 1,00 .

\section{Saran}

Adapun saran untuk penelitian lebih lanjut adalah alat dapat dikembangkan dengan penambahan beberapa sensor misalnya sensor $\mathrm{pH}$, osmosis dan sistem pengolahan dan penyaringan air menggunakan sistem osmosis, filtrasi maupun ultraviolet. Selain itu sistem monitoring berbasis PC diperlukan untuk merekam data secara cepat dan tepat selama proses pengolahan air terus berlangsung.

\section{DAFTAR PUSTAKA}

[1] Kumalasari. 2003. Taknik Praktis Mengolah Air Kotor Menjadi Air Bersih Hingga Layak Minum. Niaga Swadaya: Jakarta 94 hal.

[2] Kementrian Kesehatan Republik Indonesia. 2010. Peraturan Menteri Kesehatan Republik Indonesia Nomor 492/MENKES/PER/IV/2010 Tentang Persyaratan Kualitas Air Minum. Menteri Kesehatan Republik Indonesia. Jakarta. $16 \mathrm{~h}$.

[3]Keputusan Menteri Kesehatan RI No.907/MENKES/SK/VII/2002. Tentang SyaratSyarat dan Pengawasan Kualitas Air Minum. Jakarta

[4] Kodoatie, Robert J. 1996. Pengantar Hidrologi. Jakarta: ANDI.

[5] Endarko dkk. 2013. Rancang Bangun Sistem Penjernihan dan Dekontaminasi Air Sungai Berbasis Biosand Filter dan Lampu Ultraviolet. Jurnal Berkala Fisika Vol. 16, No. 3 ISSN: 1410-9662.

[6] Quddus, Rachmat. 2014. Teknik Pengolahan Air Bersih dengan Sistem Saringan Pasir Lambat (DOWNFLOW) yang Bersumber dari Sungai Musi. 
Jurnal Teknik Sipil dan Lingkungan Vol. 2 ISSN: 2355-374X.

[7] Sarikusmayadi, Astri Aprillia. 2015. Teknologi Pengolahan Air untuk Kondisi Darurat. ITB: Bandung.

[8] Rakhmawati, Renny dkk. 2014. Otomatisasi Sistem Pemgolahan Air Laut Menjadi Air Tawar dengan Prinsip Reverse Osmosis Berbasis Mikrokontroler. PENS: Surabaya.

[9] Untari, Tanti dan Kusnadi, Joni. 2015. Pemanfaatan Air Hujan Sebagai Air Layak Komsumsi di Kota Malang dengan Metode Modifikasi Filtrasi Sederhana. Jurnal Pangan dan Agroindustri Vol. 3 No 4 p. $1492-1502$.

[10] Handriyanto. 2010. Pendeteksian Gas Klor dan Analisis Air PDAM di Titik Terjauh dan Pemahaman Masyarakat Terhadap Gas Klor di Wilayah Pelenggan IPA Jurug Kota Surabaya. Skripsi. Universitas Sebelas Maret.

[11] Arsyad, Sitanala. 1989. Konservasi Tanah dan Air. Bogor: IPB Press.

[12] Arsyad, Sitanala. 1989. Konservasi Tanah dan Air. Bogor: IPB Press.

[13] Willshaw, G.A.,, Cheasty, T. Dan Smith, H.R. 2000 Escherichia coli dala,: . Bogor: IPB PreLund, B.M., Baird-Parker, T.C and Gould, G.W (ed). The Microbiological Safety and Quality of Food.Volume II, hal 1136 1164. Aspen Publishers, Inc. Gaithersburg, Maryland .ss.

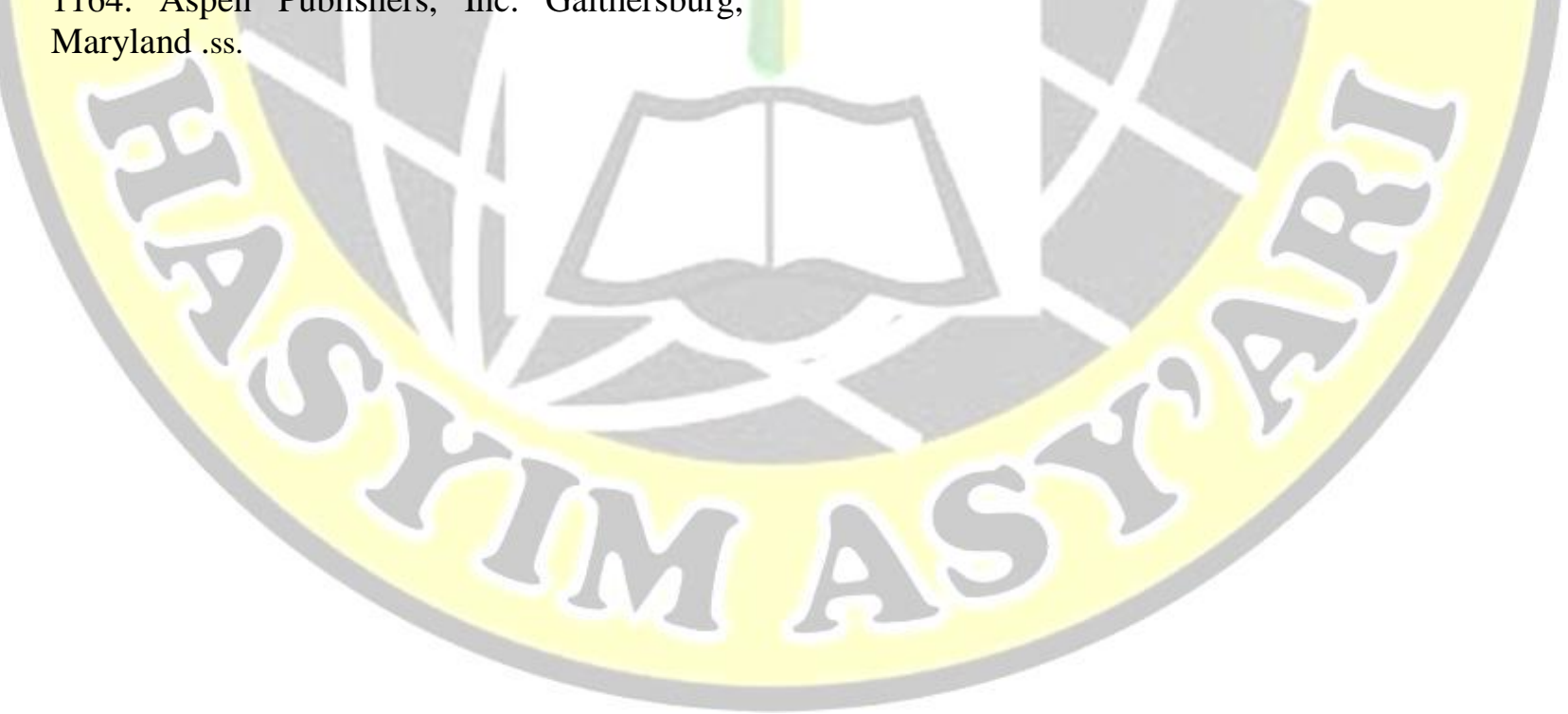

